\title{
Quantification of termite bioturbation in a savannah ecosystem: Application of OSL dating
}

Kristensen, Jeppe Ågård; Thomsen, Kristina Jørkov; Murray, Andrew; Buylaert, Jan-Pieter; Jain, Mayank; Breuning-Madsen, Henrik

\section{Published in:}

Quaternary Geochronology

Link to article, DOI:

10.1016/j.quageo.2015.02.026

Publication date:

2015

Document Version

Peer reviewed version

Link back to DTU Orbit

Citation (APA):

Kristensen, J. Å., Thomsen, K. J., Murray, A., Buylaert, J-P., Jain, M., \& Breuning-Madsen, H. (2015). Quantification of termite bioturbation in a savannah ecosystem: Application of OSL dating. Quaternary Geochronology, 30(Part B), 334-341. https://doi.org/10.1016/j.quageo.2015.02.026

\section{General rights}

Copyright and moral rights for the publications made accessible in the public portal are retained by the authors and/or other copyright owners and it is a condition of accessing publications that users recognise and abide by the legal requirements associated with these rights.

- Users may download and print one copy of any publication from the public portal for the purpose of private study or research.

- You may not further distribute the material or use it for any profit-making activity or commercial gain

- You may freely distribute the URL identifying the publication in the public portal 


\title{
Quantification of termite bioturbation in a savannah ecosystem: application of OSL dating
}

\author{
Jeppe Aa. Kristensen ${ }^{1 *}$, Kristina J. Thomsen ${ }^{2}$, Andrew S. Murray ${ }^{3}$, Jan-Pieter Buylaert ${ }^{2,3}$, Mayank Jain², Henrik \\ Breuning-Madsen ${ }^{1}$ \\ ${ }^{1}$ Department of Geosciences and Natural Resource Management, University of Copenhagen, Denmark \\ ${ }^{2}$ Center for Nuclear Technologies, Technical University of Denmark, DTU Ris $\varnothing$ Campus, Roskilde, Denmark \\ ${ }^{3}$ Nordic Laboratory for Luminescence Dating, Department of Geoscience, Aarhus University, Ris $\varnothing$ Campus, Roskilde, \\ Denmark \\ *Corresponding author: aagaard1986@gmail.com
}

Keywords: Bioturbation; Macrotermes natalensis; soil formation; luminescence dating

\begin{abstract}
Luminescence dating is one of the most promising techniques available for studying bioturbation on pedological timescales. In this study, we use multi-grain and single-grain quartz OSL to quantify termite bioturbation processes (Macrotermes natalensis) in a savannah ecosystem in Ghana. Termites transport soil from depth to the surface to construct termitaria. Over time, erosion levels these mounds and returns the sediment to the soil surface. These two processes of construction and erosion together represent an upward "conveyor belt" sediment transport process. We find that the sediment is effectively bleached during the erosion process allowing us to quantify retrospectively, for the first time, the surface deposition rate, the inverse of the upwards transport rate. At this site, this is $\sim 0.28 \mathrm{~mm}_{\text {year }}{ }^{-1}$ and began about 4.000 years ago. Downward mixing through subsurface galleries may replace $10-20 \%$ of the volume $\mathrm{ka}^{-1}$ below the unit formed by reburied termite deposits.
\end{abstract}

\section{Introduction}

Bioturbation has been a challenging topic within soil and ecosystem studies since Darwin (1881). The process has traditionally been quantitatively studied by direct observation over timespans of years to a few decades or by qualitative observations and assumptions about soil forming processes (e.g. Darwin, 1881; Lee and Wood, 1971; Lepage, 1984; Wood, 1988; Abe et al., 2000; Johnson et al., 2005).

Luminescence provides a tool for examining the continuous processes of sediment exposure at the surface and reburial by new sediment on a time scale of hundreds to thousands of years. Conventional multigrain OSL dating shares a well-known assumption with most other methods for dating sediment, namely that postdepositional vertical mixing is negligible. This assumption is clearly inconsistent with the existence of bioturbation. However, single grain OSL dating involves the measurement of doses recorded by individual grains; grains admixed from much younger or older layers can, at least in principle, be identified and omitted. If, in addition, this approach is to be used to quantify bioturbation, i.e. the amount of sediment moved by organisms after primary deposition or soil formation, any lateral processes must either be accounted for or assumed negligible. Recently, various groups have attempted to estimate bioturbation rates and incorporate them into landscape models (e.g. Heimsath et al., 2002; Stockmann et al., 2013; Johnson et al., 2014). Previous terrestrial studies argue for an exponential age development down through 
the soil profile, thought to be the consequence of "diffusion" mixing where sediment is moved randomly in three dimensions. Then an approximately exponential increase in OSL ages results from the increasing distance to the surface and the decreasing density of organisms with increasing depth. However, Madsen et al. (2011) identifies a linear dependency of age on depth on a tidal flat in which bioturbation is dominated by lugworms; they argued that their observations were more consistent with a "conveyor belt" type of transport rather than typical mixing. The current study sought to investigate a corresponding simple terrestrial ecosystem, with only one dominant bioturbating agent. Besides the obvious gains in ecosystem understanding, this study allows us to test the applicability of OSL in bioturbation studies, a major challenge for the luminescence community (Bateman et al., 2003; 2007a; 2007b).

In this paper, we use multi- and single-grain OSL signals from quartz extracted from samples taken from in and below an active termite mound in Ghana to investigate the degree of resetting of the signals, and the manner in which the ages increase with depth. We first examine the luminescence characteristics of the extracted quartz, and then attempt to quantify the bioturbation rate. Finally, the results are discussed based on a conceptual model and the depth/age relationship obtained with different statistical models.

\subsection{Study site}

The field site is a recently cultivated agricultural field on a coastal savannah in SE Ghana (N5 ${ }^{\circ} 39^{\prime} 25.5^{\prime \prime}$ W0 ${ }^{\circ} 11^{\prime} 32.6^{\prime \prime}$, Figure 1A); Macrotermes natalensis termites are the dominant bioturbating agent. Historical satellite imagery confirms that the site has only been cultivated since 2008; the termite mound was already in place at that time, and hence is not related to cultivation (Figure 1B). The mound is located on a gently sloping inselberg (4-5\%) in a mid-slope environment. Net lateral sediment transport in the local study area was assumed negligible, as input is often considered equal to output in mid-slope environments on our timescales; i.e. soil equilibrium is assumed. The parent material of the soil at our site is likely to be a mix of upslope material and in situ weathered rock - both of granitic origin. Archaeological evidence suggests that agricultural intensification and forest clearing in West Africa began about 3-4,000 years ago (Sowunmi, 1985; Stahl, 1993). Thus, the current savannah soil ecosystem, dominated by termite activity, is believed to have been present for a similar amount of time. The soil profile can be divided into four units based on the conceptual model (Figure 2) and qualitative analysis of the profile wall (Figure 1C). These units will form the basis for the analysis of the OSL-results from the soil profile.

\section{Method}

\subsection{Fieldwork and sample preparation}

The samples were collected as outlined in Figure 2. A hand auger was used to extract samples from the mound and from the very bottom of the soil profile. All other samples were extracted from the side of a profile wall at night. Standard chemical preparation (Wintle, 1997) was performed on the 90-180 $\mu \mathrm{m}$ fraction; this was used for both multi- and single-grain OSL analyses.

\subsection{Instrumentation}

All OSL measurements were performed using a Ris $\varnothing$ TL/OSL DA-20 reader (Bøtter-Jensen et al., 2010) equipped with an array of infra-red (IR, $870 \pm 40 \mathrm{~nm})$ and blue $(470 \pm 30 \mathrm{~nm})$ stimulation LEDs giving stimulation powers of $\sim 130 \mathrm{~mW}$ and $80 \mathrm{~mW} \mathrm{~cm}^{-2}$, respectively. Single-grain measurements were undertaken using a Ris $\varnothing$ single-grain laser attachment (Bøtter-Jensen et al., 2003) in which the optical stimulation light 
source is a $10 \mathrm{~mW} \mathrm{Nd:YVO}$ solid-state diode pumped laser $(532 \mathrm{~nm})$. Detection was through $7.5 \mathrm{~mm}$ of Hoya U-340 filter using an EMI 9635QA photomultiplier.

\subsection{OSL measurements}

Individual multi-grain dose estimates were measured using a SAR protocol (Murray and Wintle, 2000). Individual dose response curves were constructed using a minimum of 4 SAR cycles in addition to a recuperation, a recycling and an IR depletion cycle. For single-grain measurements a double SAR procedure (Banerjee et al., 2001) with IR stimulation at $125^{\circ} \mathrm{C}$ for $40 \mathrm{~s}$ prior to green laser stimulation at $125^{\circ} \mathrm{C}$ for 0.9 $\mathrm{s}$ was used. A high temperature bleach (using the blue LEDs) at $280^{\circ} \mathrm{C}$ for $40 \mathrm{~s}$ was inserted in between each SAR cycle to minimize potential recuperation effects (Murray and Wintle, 2003). A standard preheat of 260 ${ }^{\circ} \mathrm{C}$ for $10 \mathrm{~s}$ and a cutheat of $220^{\circ} \mathrm{C}$ were used for all measurements unless otherwise stated. Individual estimates of uncertainty are based on Poisson statistics and curve fitting errors (unless otherwise specifically stated).

For multi-grain measurements ( 1000 grains in each aliquot) the OSL signals were summed over the initial $0.8 \mathrm{~s}$ and corrected for background using the following $0.8 \mathrm{~s}$ of stimulation. The single-grain OSL signals were summed over the initial $60 \mathrm{~ms}$ with a background estimated from the final $150 \mathrm{~ms}$ of stimulation.

All dose response curves have been fitted using a saturating exponential $\left(L_{x} / T_{x}=A \times\left[1-\exp \left(D / D_{0}\right)\right]\right)$. For all samples (except for the two uppermost soil samples 145605 and -06) a significant number of sensitivity corrected natural signals $\left(L_{n} / T_{n}\right)$ did not give rise to finite doses when interpolated onto the individual dose response curves, i.e. these grains/aliquots are said to be saturated. Here we define saturation to be those grains/aliquots for which $L_{n} / T_{n}+\sigma_{L n / T n}>A$, where $\sigma_{L n / T n}$ is the uncertainty assigned to the sensitivity corrected natural signal and $A$ is the saturation value of the saturating exponential used to fit the dose response curves.

In single-grain measurements standard single-grain rejection criteria were employed: i) the uncertainty on the natural test dose $\mathrm{s}_{T_{n}}>30 \%$, ii) recycling ratio outside 2 standard errors of unity, iii) IR depletion ratio (Duller, 2003) outside 2 standard errors of unity and recuperation statistically larger than $0.1 \mathrm{~Gy}$. However, it must be noted that application of these standard rejection criteria to both dose recovery and natural dose distributions does not change either the central dose (CAM, Galbraith et al., 1999) or the observed relative overdispersion (OD) of the data significantly. The only effect of applying these rejection criteria is to reduce the number of accepted grains (by $\sim 10 \pm 1 \%, n=31$ samples) and thus there appears to be benefit from applying these criteria. Similar observations have been reported by Thomsen et al., 2012; Geach et al. (these proceedings); Guérin et al. (submitted); Hansen et al. (submitted); Thomsen et al. (submitted) and Zhao et al. (these proceedings) using samples of different origin. Nonetheless, we have chosen to employ the above mentioned rejection criteria to make this study comparable to other single-grain studies.

\subsection{Dose rate measurements}

Dose rates were determined using high-resolution gamma spectrometry (Murray et al., 1987) and the conversion factors of Guérin et al. (2011). Crushed and homogenised samples were mixed with wax and cast in a fixed disk-shaped geometry. To ensure equilibrium between ${ }^{222} \mathrm{Rn}$ and ${ }^{226} \mathrm{Ra}$, these casts were then stored for a minimum of 20 days before counting. Cosmic ray contributions are based on Prescott and Hutton (1994), and water contents on measured (field) values. Total dose rates as well as water content and radionuclide activity concentrations are given in Appendix $\mathrm{A}$.

\section{Results}




\subsection{Luminescence characteristics}

The quartz is dominated by the fast component and considered well behaved. A representative blue stimulation curve (natural dose) is shown in the inset to Figure 3a. In Figure 3a a representative dose response curve is shown. Note the low $D_{0}$ value of $36 \pm 2 \mathrm{~Gy}$. The average $\mathrm{D}_{0}$ value of all complete multi-grain dose response curves is $48 \pm 0.7 \mathrm{~Gy}(\mathrm{n}=30)$. Figure $3 \mathrm{~b}$ shows all multi-grain recycling ratios in a histogram ( $n=276$, all aliquots). No preheat dependency on the dose was detectable, neither when tested with fixed $\left(160^{\circ} \mathrm{C}\right)$ nor varying cutheat $\left(120-260^{\circ} \mathrm{C}\right)$, and the dose recovery was satisfactory over the entire $160-300^{\circ} \mathrm{C}$ preheat interval (avg $=0.970 \pm 0.004)$, on doses ranging from $\sim 0.5-2$ times the natural dose. Standard $260 / 220^{\circ} \mathrm{C}$ preheat/cutheat temperatures were chosen for the routine measurement protocol.

The single grain characteristics were equally satisfactory. Using a test dose of 4 Gy led to an average of $\sim 74 \pm 2 \%$ detectable grains (i.e. grains for which the uncertainty of the test dose OSL response was known to better than 30\%). In Figure 4 we show a dose recovery dose distribution for sample 145616. Prior to giving an in situ beta dose (10 Gy) 300 individual grains were bleached twice with the blue LEDs for $100 \mathrm{~s}$ interspaced by a pause of $10,000 \mathrm{~s}$ to allow charge trapped in the $110^{\circ} \mathrm{C}$ TL peak to decay. The arithmetic average beta dose recovery ratio was $1.03 \pm 0.02(n=193)$ and the corresponding CAM ratio is $0.99 \pm 0.01$ with a relative over-dispersion of $10.51 \pm 0.15 \%$. Single-grain thermal transfer was measured for three samples $(145605,-06,-16)$ using 300 grains for each sample and found, on average, to be $0.02 \pm 0.01$ Gy (unlogged Central Age Model, CAM UL, Arnold et al., 2009).

\subsection{Age development with depth}

All multi-grain equivalent doses and resulting ages are summarised in Appendix B. The multi-grain ages are based on simple arithmetic dose averages and increase almost exponentially with depth, down to $140 \mathrm{~cm}$ (Figure 5A). Below this, the ages cease to increase, and become very scattered, with typical doses of $~ 75-100$ $\mathrm{Gy}$, which is close to the average $2 \mathrm{xD}_{0}$ value of $96 \pm 1.5 \mathrm{~Gy}$. These data suggest field saturation. Since vertical mixing in the units above $140 \mathrm{~cm}$ was anticipated, we then moved to single grain analysis.

The single grain doses and resulting ages are summarised in Appendix B. 22 of the 31 measured natural dose distributions contained non-positive dose estimates; i.e. statistical models relying on the log-normal assumption cannot be applied. For consistency, we have used the CAM $u$ ( unlogged CAM) model to calculate weighted average doses and relative over-dispersions. For the nine samples where both CAM uL and CAM could be applied the ratio of the resulting dose estimates is $1.00 \pm 0.02(n=9)$ and between the ODs $0.77 \pm 0.02$. Above $100 \mathrm{~cm}$ (unit II), from visual inspection most single grain dose distributions appear to be relatively well bleached (e.g. contrast Figure $6 \mathrm{~b}$ and $6 \mathrm{C}$ ) although the relative over-dispersions range

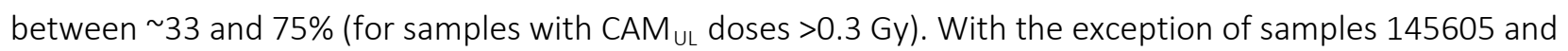
06 , all these samples contain a few saturated grains (0.5-4\% of the otherwise accepted grain population). In the 100-140 cm interval (unit III) the single-grain dose distributions appear positively skewed (Figure 6D), but their over-dispersion values of $\sim 50 \%$ are not significantly different from those from unit II. According to the conceptual model (Figure 2), this unit consists primarily of unexposed parent material so the unsaturated OSL signals from some grains may be due to downward mixing of young surface grains through the subsurface galleries, in a similar fashion as Rink et al. (2013) found for ant galleries. Below $140 \mathrm{~cm}$ (unit IV) less than $50 \%$ of the natural sensitivity corrected signals intersect the dose response curves, so this unit is clearly OSL saturated, as suggested by the large aliquot data. Single-grain ages are shown in Figure 5; these were calculated by applying the following statistical models to the dose distributions: (i) the average weighted doses (CAM ${ }_{U L}$ ), (ii) the minimum doses using a minimum age model (IEU, Thomsen et al., 2003; 2007) and (iii) finite mixture doses using the Finite Mixture Model (FMM, Galbraith and Green, 1990). The 
IEU model was run with a relative OD of 30\%. The FMM was run using OD values ranging between 10 and $40 \%$. The OD was chosen by optimising the BIC and llik scores (Galbraith, 2005) and found to be $20 \%$ for most samples. Negative dose values were arbitrarily discarded before running the FMM. The ages presented in Figure 5 and Appendix $B$ are based on the most prominent dose component (the $P$ values are stated). In the following section we will discuss which of these models are most appropriate for these samples.

\section{Discussion}

According to the conceptual model (Figure 2), the primary bioturbation process in unit II is expected to be dominated by a 'conveyor belt' process where the sediment at the surface is reburied by new sediment brought up from depth; post-depositional mixing is expected to be negligible. If this assumption is true and the bioturbation rate was constant over the entire time interval, the OSL ages would be expected to increase linearly with depth. However, this model requires that the mound material is effectively zeroed when it is washed off the mound and into the pediment.

Figure 6A shows that the dose distribution in the pediment (unit I) is indeed narrow and yield ages (Table 2) within the typical lifecycle of a mound of 20-80 years (Abe et al., 2000). Doses contained by surface grains on an adjacent termite mound (CAM=0.74 $\pm 0.11 \mathrm{~Gy}$, sample 145633, Appendix B) suggest that the grains are first effectively bleached during the wash-off erosion into the pediment, although some grains on the surface are well-bleached (IEU=-0.06 $\pm 0.05 \mathrm{~Gy}$ ). This is similar to what Bateman et al. (2003) suggested for gopher mounds, although they did not have sufficient data to examine it properly.

The dose distributions in the upper $100 \mathrm{~cm}$ of the soil (unit II), presumed to have been deposited by termites, also suggest well-bleached populations (Figure 6B-C). We conclude that there is no evidence to discount the conveyor belt mixing model; significant vertical post-depositional mixing would presumably have yielded a wider and more skewed dose distribution. In the 100-140 cm interval (unit III) the single grain distributions are more positively skewed (Figure 6D).

When the different age models are applied in unit II certain patterns appear. Conceptually, the average (or $\mathrm{CAM}_{\cup L}$ ) ages should be closest to the true age. The multi-grain ages consistently overestimate CAM $\mathrm{M}_{\cup}$ single grain ages by $0.68 \pm 0.13 \mathrm{ka}$ on average, presumably due to the small fraction of saturated grains present in each sample (Figure $5 \mathrm{C}$ ). These saturated grains are probably grains dropped or deposited by the termites on the way to the nest on the surface; this was also suggested by Rink et al. (2013) in ant galleries. Thus, a small number of saturated grains are in fact mixed upwards into the overlying horizons, although the majority are successfully brought to the surface. However, this process is seemingly unable to skew the distributions in unit II significantly.

The FMM (Roberts et al., 2000) main components are consistent with the CAM ages. The FMM main component represents, on average, $64 \pm 6 \%$ of the grains (range: $45-97 \%$ ) with preset OD values of $20 \%$ commonly yielding the best results (range tested: $10-40 \%$ ), although a minimum of 4 components were identified irrespective of the OD. The overdispersion of the single-grain distributions from the soil profiles range between $33 \pm 3$ and $74 \pm 9 \%$ (Appendix B). In all samples from unit I and the top of unit II (above $27 \mathrm{~cm}$ ) more than $5 \%$ of the grains yield negative doses. Thus, they are unsuited for analysis using the FMM, which significantly weakens the conclusions based on this model for young sediments. Fundamentally, each layer is unlikely to be made up of a mixture of a finite number of source sediments, so the basic assumptions of the model are clearly not satisfied. The dose distributions suggest that the samples in this unit are well-bleached, and so there is no good argument for applying the IEU model either. However, the IEU age development 
follows the CAM ages, although they are a little off to the negative side, which was expected. Therefore, we conclude that the CAM ages are the best estimate of the actual age.

The CAM ages are consistent $\left(R^{2}=0.97\right)$ with a linear accumulation rate of $0.28 \mathrm{~mm}$ year ${ }^{-1}$. As lateral sediment transport is assumed negligible, this rate equals the upward transport rate due to termite activity, and it is within the ranges of literature values (for reviews see Lee and Wood, 1971; Wood, 1988; Lobry de Bruyn and Conacher, 1990). The intercept of the regression line is indistinguishable from the origin, which suggests that the surface grains should have a negligible dose, which is confirmed by the distribution in Figure 6A.

Inspired by the work of Murray et al. (1992) ${ }^{226} \mathrm{Ra} /{ }^{232}$ Th was plotted against depth (Figure 7). This reveals that the signal in the termite mound is indistinguishable from the signal in the soil profile above $100 \mathrm{~cm}$ but different from signal from the soil below. The simplest interpretation is that the termites source their sediment from the top meter, which contradicts the conceptual model. Alternatively, the unit could consist of former mound pediment material, as the model suggests (Figure 2). The latter would imply that the termites alter the ${ }^{226} \mathrm{Ra} /{ }^{232} \mathrm{Th}$ relative to the bulk source soil upon transportation to the surface.

The soil physical and chemical properties correspond to what previous authors have found in studies of savannah termites (Lobry de Bruyn and Conacher, 1990) and similar to what some of the architects behind the conceptual model found (Nye, 1955; Awadzi et al., 2004; Breuning-Madsen et al., 2007). The topsoil is gravel free, as is the termite mound itself, despite the presence of considerable amounts of gravel in the soil below (Kristensen, 2014). A comparison between the clay contents in the soil profile and the overlying mound suggests that the termites must excavate at least some sediment below $100 \mathrm{~cm}$ (unit III) with more than $18 \%$ clay in order to reach the mound content of $12 \%$, as the content in the gravel free topsoil (unit II) and the pediment (unit I) is only $7 \%$. The number of saturated grains in the mound is higher than in the upper $100 \mathrm{~cm}$ of the soil profile (Appendix B), which also suggests that parts of the sediment must be sourced below $100 \mathrm{~cm}$. On the contrary, some of the grains must also be sourced in unit II to end up with the particle size distribution and fraction of saturated grains found in the mound. We cannot unambiguously identify the dominant sediment source, which gives rise to the mound characteristics (and at least in principle there may not be such a source). Thus, we cannot ultimately decide between the two possible reasons for the pattern in ${ }^{226} \mathrm{Ra} /{ }^{232} \mathrm{Th}$ and it may be a combination, which corresponds to the conclusion of Awadzi et al. (2004) and Breuning-Madsen et al. (2007) made on similar soil physical and chemical datasets in their studies of forest termites in Ghana. However, one should be careful when comparing different termite groups as they modify the soil profile differently. Despite the challenge of identifying the primary mining area, the linear increase in $C A M_{U L}$ age with depth (Figure $5 C$ ) in the gravel free topsoil $(0-100 \mathrm{~cm})$ of the current study is difficult to explain without all grains being delivered to the surface (and so bleached) before reburial, i.e. the conveyor belt model. Significant vertical mixing from deeper (non-zeroed) or surface (0-age) sources would give less well-bleached distributions, and so larger differences between IEU, CAM and multi-grain doses and a non-linear CAM age relationship with depth (Bateman et al., 2007b). The latter would also be expected if significant post-depositional mining in unit II took place.

Given this model, we postulate that sediment from the $100-140 \mathrm{~cm}$ interval has not been at the surface during the lifetime of the current soil-formation processes; the OSL signal in material originally from this unit is probably saturated, as in the unit below. However, the average multigrain OSL signals $\left(L_{N} / T_{N}\right)$ from this unit are not in fact saturated, and we suggest that this is most likely because of downward mixing of grains from the surface due to downwash through the abundant subsurface galleries (see picture of unit II in Figure 1C). This is supported by the IEU-ages, which is considerably younger than the CAM ages (Appendix B and Figure 5B). However it cannot be concluded whether these grains represent real mixing, or simply the so called 'zero-grains' known from numerous other studies (Arnold and Roberts, 2011; Demuro et al., 2012). If 
we make the simplifying assumption that this mixing is primarily between recently zeroed grains and saturated grains, the light reduction (dilution) of the saturation luminescence intensity can be directly translated into volumetric replacement of saturated grains by zero-age grains, to give a downward mixing rate of about 10 to $20 \% \mathrm{v} \mathrm{ka}^{-1}$. Since this process has been going on for $\sim 4 \mathrm{ka}$ (oldest age of the wellbleached unit above), it would appear that about $40-70 \%$ of the volume of the $100-140 \mathrm{~cm}$ unit has been mixed in from the upper layers; the volume of young grains decreases with depth, as the termites gradually mine deeper and deeper.

\section{Conclusions}

Bioturbation can complicate the measurement of reliable OSL doses, particularly from terrestrial environments. This study shows that this can apply even to older underlying material, but that careful analysis of single grain OSL dose distributions can yield satisfactory dates from bioturbated soils and underlying sterile material, given some information about the ecosystem involved.

For the current system CAM seem to be the most appropriate for extracting reliable doses from the single grain dose distributions; multi-grain ages overestimate, presumably because of a few saturated grains, but FMM, IEU and CAM are more or less consistent with each other in the depth interval believed to represent biologically transported, zeroed and then reburied sediment $(0-100 \mathrm{~cm})$. The IEU model probably underestimates the age in some layers, because of the presence of a small number of grains with unusually low doses; it is not known if these few grains represent real mixing, or simply the so called 'zero-grains' often reported in other studies. Although the main component of the FMM also seems to identify the appropriate dose, it could not be applied to the youngest layers (with some negative doses), and in any case the age mixtures cannot credibly be argued to be made up of a small number of components. The few saturated grains identified in the upper $100 \mathrm{~cm}$ are presumed to reflect the occasional loss of grains by the termites mining sediment from the deep source (with saturated grains) and carrying them to the mound on the surface. The CAM considers the entire dose distribution; grains with natural signals that do not intersect the growth curve are rejected before statistical analysis. In addition, there are only a few grains close to saturation and these usually have much larger relative uncertainties than grains recording a small dose. The CAM ages suggest a surface accumulation rate of $0.28 \mathrm{~mm}_{\text {year }}{ }^{-1}$ over the last 3-4,000 years. Below $100 \mathrm{~cm}$ the average ages (multigrain and single-grain CAM) increase rapidly with depth while the IEU age drops; this is thought to be a consequence of downward movement of young surface grains through the subsurface galleries into the initially saturated mining area $(100-140 \mathrm{~cm})$. Below this depth the OSL signal is saturated and presumed to be essentially unaffected by the current termite bioturbation process.

Using luminescence dating, it has proved possible, for the first time, to argue convincingly for a vertical, biological conveyor belt transportation process in a terrestrial ecosystem, and to quantify the rate of the process. Quantitative understanding of such processes is very important to our understanding of landscape formation, soil fertility and element cycling. Further methodological development is needed in order to apply this approach to more complicated ecosystems and in order to incorporate them in landscape models. Nevertheless, we hope these results will encourage further work into the application of luminescence in studies of bioturbation, and in soil science in general. 


\section{References}

Abe, Y., Bignell, D.E., Higashi, T., 2000. Termites: Evolution, Sociology, Symbioses, Ecology. Springer-Verlag, NY, US, $488 \mathrm{p}$.

Arnold, L.J., Roberts, R.G., Galbraith, R.F., DeLong, S.B., 2009. A revised burial dose estimation procedure for optical dating of young and modern-age sediments. Quaternary Geochronology 4: 306-325

Arnold, L., Roberts, R.G., 2011. Paper I - Optically stimulated luminescence (OSL) dating of perennially frozen deposits in north-central Siberia: OSL characteristics of quartz grains and methodological considerations regarding their suitability for dating. Boreas 40: 389-416.

Awadzi, T.W. Cobblah, M.A., Breuning-Madsen, H., 2004. The role of termites in soil formation in the tropical semi-deciduous forest zone, Ghana. Danish Journal of Geography 104(2): 27-34

Banerjee, D., Murray, A.S., Bøtter-Jensen, L., Lang, A., 2001. Equivalent dose estimation using a single aliquot of polymineral fine grains. Radiation Measurements 33: 73-94.

Bateman, M.D., Boulter, C.H., Carr, A.S., Frederick, C.D., Peter, D., Wilder, M., 2007a. Detecting postdepositional sediment disturbance in sandy deposits using optical luminescence. Quaternary Geochronology 2: 57-64.

Bateman, M.D., Boulter, C.H., Carr, A.S., Frederick, C.D., Peter, D., Wilder, M., 2007b. Preserving the palaeoenvironmental record in Drylands: Bioturbation and its significance for luminescence-derived chronologies. Sedimentary Geology 195: 5-19.

Bateman, M.D., Frederick, C.D., Jaiswal, M.K., Singhvi, A.K., 2003. Investigations into the potential effects of pedoturbation on luminescence dating. Quaternary Science Reviews 22(10-13): 1169-1176.

Breuning-Madsen, H., Awadzi, T.W., Koch, C.B., Borggaard, O.K., 2007. Characteristics and genesis of pisolitic soil layers in a tropical moist semi-deciduous forest of Ghana. Geoderma 141(1-2): 130-138

Bøtter-Jensen, L., Andersen, C.E., Duller, G.A.T., Murray, A. S., 2003. Developments in radiation, stimulation and observation facilities in luminescence measurements, Radiation Measurements 37(4-5): 535-541.

Bøtter-Jensen, L., Thomsen, K.J., Jain, M., 2010. Review of optically stimulated luminescence (OSL) instrumental developments for retrospective dosimetry. Radiation Measurements 45: 253-257.

Darwin, C., 1881. The formation of vegetable mould through the action of worms, with observations on their habits. John Murray, London, UK.

Demuro, M., Froese, D.G., Arnold, L.J., Roberts, R.G., 2012. Single-grain OSL dating of glaciofluvial quartz constrains Reid glaciation in NW Canada to MIS 6. Quaternary Research 77: 305-316.

Duller, G.A.T., 2003. Distinguishing quartz and feldspar in single grain luminescence measurements. Radiation Measurements 37: 161-165.

Galbraith, R., 2005. Statistics for Fission Track Analysis. Boca Raton, FL, USA. Chapman \& Hall/CRC

Galbraith, R. F., Green, P. F., 1990. Estimating the component ages in a finite mixture. Nuclear Tracks and Radiation Measurements 17: 196-206 
Galbraith, R.F., Roberts, R.G., Laslette, G., Yoshidda, H., Olley, J., 1999. Optical dating of single and multiple grain quartz from Jinmium rock shelter, northern Australia. Part I. Experimental design and statistical models R.F. Archaeometry 41: 339-364

Geach, M.R, Thomsen, K.J., Buylaert, J.-P., Murray, A.S., Mather, A.E., Telfer, M.W., Stokes, M, These proceedings. A chronological framework for the Quaternary landform records of the Tabernas Basin, SE Spain. Submitted to Quaternary Geochronology.

Guérin, G., Frouin, M., Talamo, S., Aldeias, V., Bruxelles, L., Chiotti, L., Dibble, H.L., Goldberg, P., Hublin, J-J., Jain, M., Lahaye, C., Madelaine, S., Maureille, B., McPherron, S.P., Mercier, N., Murray, A.S., Sandgathe, D., Steele, T.E., Thomsen, K.J., Turq, A., Submitted. A Multi-method Luminescence Dating of the Palaeolithic Sequence of La Ferrassie Based on New Excavations Adjacent to the La Ferrassie 1 and 2 Skeletons. Submitted to Journal of Arhaeological Science.

Guérin, G., Mercier, N., Adamiec, G., 2011. Dose-rate conversion factors: update. Ancient TL 29(1): 5-8. Hansen, V., Murray, A.S., Buylaert, J-P., Yeo, E-Y., Thomsen, K.J., Submitted. A new irradiated quartz for beta source calibration. Submitted to Radiation Measurements.

Heimsath, A.M., Chappell, J., Spooner, N.A., Questiaux, D.G., 2002. Creeping soil. Geology, 30(2): 111-114 Johnson, D.L., Domier, J.E.J., Johnson, D.N., 2005. Reflections on the nature of soil and its biomantle. Annals of the Association of American Geographers 95: 11-31

Johnson, M.O., Mudd, S.M., Pillans, B., Spooner, N.A., Fifield, L.K., Kirkby, M.J., Gloor, M., 2014. Quantifying the rate and depth dependence of bioturbation based on optically-stimulated luminescence (OSL) dates and meteoric ${ }^{10} \mathrm{Be}$. Earth Surface Processes and Landforms, Early view.

Kristensen, J.A., 2014. OSL as a tool for fingerprinting sediment and quantifying bioturbation in a savannah ecosystem. M.Sc. thesis. University of Copenhagen. Denmark. Unpublished.

Lee, K. E. \& Wood, T. G., 1971. Termites and soils. Academic Press (Inc.) London Ltd. UK. 251 p.

Lepage, M., 1984. Distribution, density and evolution of Macrotermes Bellicosus nests (Isoptera:

Macrotermitinae) in the north-east of Ivory Coast. Journal of Animal Ecology 53: 107-117

Lobry de Bruyn, L.A., Conacher, A.J., 1990. The Role of Termites and Ants in Soil Modification: A Review. Australian Journal of Soil Research 28: 55-93.

Madsen, A.T., Murray, A.S., Jain, M., Andersen, T.J., Pejrup, M., 2011. A new method for measuring bioturbation rates in sandy tidal flat sediments based on luminescence dating. Estuarine, Coastal and Shelf Science 92(3): 464-471.

Murray, A.S., Marten, R., Johnson, A., Martin, P., 1987. Analysis for naturally occurring radionuclides at environmental concentrations by gamma spectrometry. Journal of Radioanalytical and Nuclear Chemistry Articles 115: 263- 288.

Murray, A.S., Olley, J.M., Wallbrink, P.J., 1992. Natural radionuclide behaviour in the fluvial environment. Radiation Protection Dosimetry 45(1/4): 285-288

Murray, A.S., Wintle A.G., 2000. Luminescence dating of quartz using an improved single-aliquot regenerative-dose protocol. Radiation Measurements 32: 57-73. 
Murray A.S., Wintle A.G., 2003. The single aliquot regenerative dose protocol: potential for improvements in reliability. Radiation Measurements 37: 377-381.

Nye, P. H., 1955. Some soil-forming processes in the humid tropics, II. The development of the upper-slope member of the catena. Journal of Soil Science 5: 7-21

Prescott, J. R., Hutton, J. T., 1994. Cosmic ray contributions to dose rates for luminescence and ESR dating: large depths and long-term variations. Radiation Measurements 23: 497-500.

Rink, W.J., Dunbar, J.S., Tschinkel, W.R., Kwapich, C., Repp, A., Stanton, W., Thulman, D.K., 2013.

Subterranean transport and deposition of quartz by ants in sandy sites relevant to age overestimation in optical luminescence dating. Journal of Archaeological Science 40: 2217-2226.

Roberts, R.G., Galbraith, R.F., Yoshida, H., Laslett, G.M., Olley, J.M., 2000. Distinguishing dose populations in sediment mixtures: a test of single-grain optical dating procedures using mixtures of laboratory-dosed quartz. Radiation Measurements 32: 459-465

Sovunmi, M.A., 1985. The beginnings of agriculture in West Africa: Botanical evidence. Current Anthropology 26: $127-129$

Stahl, A.B., 1993. Intensification in the West African Late Stone Age: A view from Central Ghana. I: The Archaeology of Africa: Foods, Metals and Towns (Shaw, C.T., Sinclair, P., Andah, B., Okpoko, A., eds.). Routledge, London, UK. pp 261-273.

Stockmann, U., Minasny, B., Pietsch, T.J., McBratney, A.B., 2013. Quantifying processes of pedogenesis using optically stimulated luminescence. European Journal of Soil Science 64(1): 145-160.

Thomsen K.J., Murray A., Jain M., 2012. The dose dependency of the over-dispersion of quartz OSL single grain dose distributions. Radiation Measurements 47, 732-739.

Thomsen, K.J., Murray, A.S., Bøtter-Jensen, L., Jungner, H., 2003. Variation with depth of dose distributions in single grains of quartz extracted from an irradiated concrete block. Radiation Measurements 37(4-5): 315321.

Thomsen, K.J., Murray, A.S., Buylaert, J.P, Jain, M., Hansen, J.H., Aubry, T., Submitted. Testing single-grain quartz OSL methods using known age samples from the Bordes-Fitte rockshelter (Roches d'Abilly site, Central France). Submitted to Quaternary Geochronology.

Thomsen, K.J., Murray, A.S., Bøtter-Jensen, L., Kinahan, J., 2007. Determination of burial dose in incompletely bleached fluvial samples using single grains of quartz. Radiation Measurements 42(3): 370-379.

Wintle, A.G., 1997. Luminescence dating: laboratory procedures and protocols. Radiation Measurements 27: 769-817.

Wood, T.G., 1988. Termites and the soil environment. Biology and Fertility of Soils 6: 228-236.

Zhao, Q.Y., Thomsen, K.J., Murray, A.S., Wei, M.J., Pan, B.L., Zhou, R., Zhao, X.H., Chen, H.Y., These proceedings. Quartz single-grain OSL dating of debris flow deposits from Miyun, north east Beijing in China. Submitted to Quaternary Geochronology. 


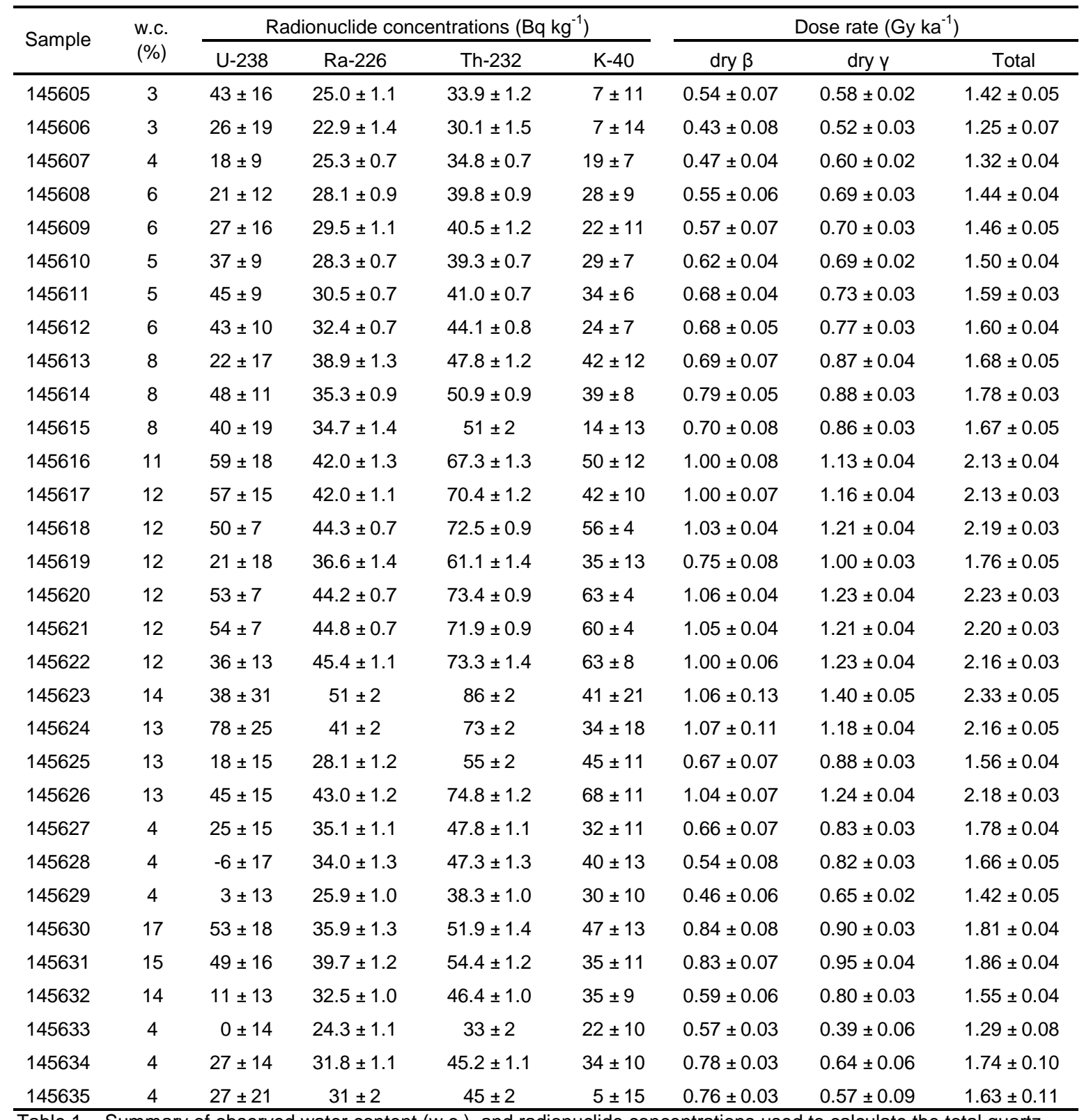

Table 1 Summary of observed water content (w.c.), and radionuclide concentrations used to calculate the total quartz dose rates. Uncertainties represent one standard error. 


\begin{tabular}{|c|c|c|c|c|c|c|c|c|c|c|c|c|c|c|c|c|c|c|c|c|c|c|c|c|c|c|c|}
\hline \multirow{3}{*}{$\begin{array}{c}\text { Unit } \\
1\end{array}$} & \multirow{3}{*}{$\begin{array}{l}\text { Sample } \\
145605\end{array}$} & \multirow{3}{*}{$\begin{array}{c}\text { Depth }(\mathrm{cm}) \\
-3\end{array}$} & \multicolumn{2}{|l|}{ Multi-grain } & \multicolumn{15}{|c|}{ Single-grain } & \multirow{2}{*}{$\frac{\text { Multi-grain }}{\text { age (ka) }}$} & \multicolumn{7}{|c|}{ Single-grain } \\
\hline & & & Dose (Gy) & \multirow{2}{*}{$\frac{n}{12}$} & \multirow{2}{*}{$\begin{array}{l}n_{\text {neg. }} \\
65 \\
\end{array}$} & $\operatorname{CAM}_{\mathrm{UL}}(\mathrm{Gy})$ & \multicolumn{2}{|c|}{$\mathrm{OD}_{\mathrm{UL}}(\%)$} & \multirow{2}{*}{$\begin{array}{ll}n \\
173\end{array}$} & \multicolumn{3}{|c|}{ IEU (Gy) } & \multirow{2}{*}{$\begin{array}{l}n_{\text {w.t. }} \\
94 \% \\
\end{array}$} & \multirow{2}{*}{\multicolumn{3}{|c|}{ FMM (Gy) }} & & \multirow{2}{*}{$\begin{array}{l}p \\
n / a \\
\end{array}$} & \multirow{2}{*}{$\begin{array}{c}\text { Sat. }(\%) \\
0\end{array}$} & & $\operatorname{CAM}_{\mathrm{UL}}(\mathrm{ka})$ & & $J(\mathrm{ka})$ & & & $\mathrm{MM}(\mathrm{k}$ & \\
\hline & & & $0.35 \pm 0.02$ & & & $0.10 \pm 0.03$ & $246 \pm$ & \pm 47 & & 0.03 & & .01 & & & & & & & & $0.25 \pm 0.02$ & $0.07 \pm 0.02$ & 0.02 & & 0.01 & & $\mathrm{n} / \mathrm{a}$ & \\
\hline "I & 145606 & 2 & $0.38 \pm 0.02$ & 11 & 35 & $0.20 \pm 0.02$ & $75 \pm$ & \pm 21 & 201 & 0.07 & \pm 0.0 & .01 & $77 \%$ & & $\mathrm{n} / \mathrm{a}$ & & & $n / a$ & 0 & $0.30 \pm 0.03$ & $0.16 \pm 0.02$ & 0.06 & \pm 0 & 0.01 & & $n / a$ & \\
\hline & 145607 & 17 & $1.48 \pm 0.08$ & 11 & 23 & $0.77 \pm 0.04$ & $76 \pm$ & \pm 8 & 345 & 0.21 & \pm 0.0 & .02 & $46 \%$ & & n/a & & & n/a & 1 & $1.11 \pm 0.09$ & $0.58 \pm 0.03$ & 0.16 & \pm 0 & 0.01 & & $\mathrm{n} / \mathrm{a}$ & \\
\hline & 145608 & 27 & $2.57 \pm 0.10$ & 12 & 4 & $1.58 \pm 0.11$ & $74 \pm$ & \pm 9 & 157 & 0.83 & \pm 0.0 & .05 & $64 \%$ & 2.2 & \pm 0.2 & .2 & $50 \%$ & \pm 0.08 & 2 & $1.76 \pm 0.12$ & $1.08 \pm 0.08$ & 0.57 & \pm 0. & 0.03 & 1.53 & \pm & 0.12 \\
\hline & 145609 & 39 & $3.37 \pm 0.18$ & 10 & 1 & $1.94 \pm 0.09$ & $53 \pm$ & \pm 5 & 192 & 1.41 & \pm 0.0 & .06 & $75 \%$ & 2.05 & \pm 0.0 & .09 & $97 \%$ & \pm 0.01 & 3 & $2.3 \pm 0.2$ & $1.32 \pm 0.06$ & 0.96 & \pm 0 & 0.04 & 1.40 & \pm & 0.06 \\
\hline & 145610 & 49 & $3.21 \pm 0.10$ & 11 & 2 & $2.50 \pm 0.10$ & $65 \pm$ & \pm 7 & 187 & 1.85 & \pm 0.0 & .06 & $81 \%$ & 2.22 & \pm 0.0 & .07 & $81 \%$ & \pm 0.04 & 0.5 & $2.13 \pm 0.13$ & $1.66 \pm 0.07$ & 1.24 & \pm 0 & 0.04 & 1.48 & \pm & 0.05 \\
\hline & 145611 & 59 & $3.73 \pm 0.13$ & 11 & 2 & $2.61 \pm 0.07$ & $33 \pm$ & \pm 3 & 331 & 2.50 & \pm 0.0 & .06 & $94 \%$ & 2.71 & \pm 0.0 & .07 & $90 \%$ & \pm 0.03 & 1 & $2.3 \pm 0.2$ & $1.64 \pm 0.04$ & 1.58 & \pm 0 & 0.04 & 1.71 & \pm & 0.04 \\
\hline & 145612 & 73 & $4.81 \pm 0.10$ & 12 & 0 & $3.80 \pm 0.10$ & $34 \pm$ & \pm 4 & 204 & 3.57 & \pm 0.1 & .10 & $91 \%$ & 4.5 & \pm 0.2 & 12 & $45 \%$ & \pm 0.12 & 2 & $3.0 \pm 0.2$ & $2.36 \pm 0.06$ & 2.23 & \pm 0. & 0.06 & 2.81 & \pm & 0.13 \\
\hline & 145613 & 83 & $6.7 \pm 0.2$ & 11 & 1 & $5.3 \pm 0.2$ & $43 \pm$ & \pm 4 & 205 & 4.63 & \pm 0.1 & 13 & $87 \%$ & 4.9 & \pm 0.4 & .4 & $62 \%$ & \pm 0.13 & 3 & $4.0 \pm 0.3$ & $3.15 \pm 0.12$ & 2.76 & \pm 0 & 0.08 & 2.9 & \pm & 0.3 \\
\hline & 145614 & 92 & $8.7 \pm 0.2$ & 12 & 0 & $5.7 \pm 0.2$ & $41 \pm$ & \pm 4 & 216 & 4.73 & \pm 0.1 & 14 & $75 \%$ & 4.4 & \pm 0.4 & 4 & $49 \%$ & \pm 0.16 & 4 & $4.9 \pm 0.3$ & $3.20 \pm 0.11$ & 2.66 & \pm 0 & 0.08 & 2.5 & \pm & 0.2 \\
\hline IIII & 145615 & 102 & $11.4 \pm 0.5$ & 11 & 0 & $6.5 \pm 0.3$ & $55 \pm$ & \pm 6 & 205 & 2.00 & \pm 0.1 & .14 & $20 \%$ & 6.6 & \pm 0.4 & 4 & $52 \%$ & $\pm \quad 0.07$ & 6 & $6.8 \pm 0.5$ & $3.9 \pm 0.2$ & 1.20 & \pm 0 & 0.08 & 4.0 & \pm & 0.3 \\
\hline & 145616 & 119 & $28 \pm 2$ & 3 & 2 & $10.1 \pm 0.4$ & $59 \pm$ & \pm 5 & 309 & 4.4 & \pm 0.2 & 2 & $31 \%$ & 8.2 & \pm 0.5 & .5 & $54 \%$ & \pm 0.0 & 28 & $13.2 \pm 1.2$ & $4.7 \pm 0.2$ & 2.07 & \pm 0 & 0.08 & 3.8 & \pm & 0.2 \\
\hline & 145617 & 139 & $73 \pm 3$ & 3 & 0 & $22.3 \pm 1.1$ & $47 \pm$ & \pm 6 & 142 & & n/a & & & 24 & \pm 2 & & $46 \%$ & \pm 0.09 & 39 & $34 \pm 2$ & $10.5 \pm 0.5$ & & $\mathrm{n} / \mathrm{a}$ & & 11.2 & \pm & 0.8 \\
\hline IV & 145618 & 160 & $75 \pm 8$ & 3 & 0 & $18.5 \pm 1.2$ & $56 \pm$ & \pm 7 & 111 & & $n / a$ & & & & $\mathrm{n} / \mathrm{a}$ & & & $\mathrm{n} / \mathrm{a}$ & 43 & $34 \pm 4$ & $8.4 \pm 0.5$ & & $\mathrm{n} / \mathrm{a}$ & & & $\mathrm{n} / \mathrm{a}$ & \\
\hline & 145619 & 183 & $100 \pm 7$ & 3 & 0 & $21.3 \pm 1.4$ & $48 \pm$ & \pm 7 & 104 & & n/a & & & & $n / a$ & & & $n / a$ & 51 & $57 \pm 5$ & $12.1 \pm 0.8$ & & $n / a$ & & & $\mathrm{n} / \mathrm{a}$ & \\
\hline & 145620 & 208 & $82 \pm 7$ & 3 & 2 & $22 \pm 2$ & $65 \pm$ & \pm 8 & 121 & & $n / a$ & & & & n/a & & & $\mathrm{n} / \mathrm{a}$ & 47 & $37 \pm 4$ & $9.8 \pm 0.7$ & & $n / a$ & & & n/a & \\
\hline & 145621 & 234 & $101 \pm 4$ & 3 & 2 & $21 \pm 2$ & $65 \pm$ & \pm 9 & 94 & & n/a & & & 29.9 & \pm 1.4 & .4 & $63 \%$ & \pm 0.07 & 56 & $46 \pm 3$ & $9.6 \pm 0.8$ & & $\mathrm{n} / \mathrm{a}$ & & 13.6 & \pm & 0.7 \\
\hline & 145622 & 258 & $102 \pm 7$ & 3 & 0 & $25 \pm 2$ & $53 \pm$ & \pm 7 & 116 & & n/a & & & & $n / a$ & & & $n / a$ & 52 & $47 \pm 4$ & $11.5 \pm 0.7$ & & n/a & & & $\mathrm{n} / \mathrm{a}$ & \\
\hline & 145623 & 292 & $190 \pm \mathrm{n} / \mathrm{a}$ & 1 & 0 & $28 \pm 2$ & $30 \pm$ & \pm 6 & 89 & & n/a & & & & n/a & & & $n / a$ & 61 & $81 \pm n / a$ & $11.9 \pm 0.6$ & & $n / a$ & & & $\mathrm{n} / \mathrm{a}$ & \\
\hline & 145624 & 302 & $131 \pm \mathrm{n} / \mathrm{a}$ & 1 & 1 & $25 \pm 2$ & $51 \pm$ & \pm 8 & 91 & & $n / a$ & & & & n/a & & & n/a & 60 & $61 \pm n / a$ & $11.7 \pm 0.8$ & & $n / a$ & & & $\mathrm{n} / \mathrm{a}$ & \\
\hline & 145625 & 312 & $107 \pm 5$ & 3 & 0 & $32 \pm 2$ & $49 \pm$ & \pm 8 & 96 & & n/a & & & & $n / a$ & & & $n / a$ & 56 & $69 \pm 5$ & $20.3 \pm 1.3$ & & $n / a$ & & & $\mathrm{n} / \mathrm{a}$ & \\
\hline & 145626 & 322 & $135 \pm 10$ & 3 & 1 & $27 \pm 2$ & $53 \pm$ & \pm 9 & 61 & & $n / a$ & & & 32 & \pm 3 & & $65 \%$ & \pm 0.17 & 70 & $62 \pm 6$ & $12.4 \pm 1.1$ & & $\mathrm{n} / \mathrm{a}$ & & 14.7 & \pm & 1.4 \\
\hline Mound wall & 145627 & -60 & $3.6 \pm 0.2$ & 12 & 18 & $1.55 \pm 0.14$ & $194 \pm$ & \pm 20 & 181 & & n/a & & & & $n / a$ & & & $\mathrm{n} / \mathrm{a}$ & 0.5 & $2.0 \pm 0.2$ & $0.87 \pm 0.08$ & & $\mathrm{n} / \mathrm{a}$ & & & $\mathrm{n} / \mathrm{a}$ & \\
\hline & 145628 & -50 & $3.5 \pm 0.2$ & 11 & 15 & $1.81 \pm 0.09$ & $135 \pm$ & \pm 15 & 169 & & $n / a$ & & & & $n / a$ & & & $n / a$ & 0.5 & $2.1 \pm 0.2$ & $1.09 \pm 0.05$ & & $n / a$ & & & $\mathrm{n} / \mathrm{a}$ & \\
\hline & 145629 & -40 & $3.9 \pm 0.2$ & 12 & 10 & $1.7 \pm 0.2$ & $190 \pm$ & \pm 27 & 155 & & n/a & & & & n/a & & & $n / a$ & 4 & $2.7 \pm 0.2$ & $1.22 \pm 0.13$ & & n/a & & & $n / a$ & \\
\hline Mound core & 145630 & -30 & $7.9 \pm 0.3$ & 11 & 13 & $2.4 \pm 0.2$ & $99 \pm$ & \pm 12 & 157 & & $\mathrm{n} / \mathrm{a}$ & & & 1.3 & \pm 0.3 & & $41 \%$ & \pm 0.11 & 5 & $4.4 \pm 0.3$ & $1.34 \pm 0.13$ & & n/a & & 0.70 & \pm & 0.15 \\
\hline & 145631 & -20 & $7.0 \pm 0.2$ & 12 & 17 & $3.1 \pm 0.2$ & $107 \pm$ & \pm 11 & 328 & & n/a & & & 2.5 & \pm 0.2 & .2 & $35 \%$ & \pm 0.05 & 6 & $3.8 \pm 0.2$ & $1.65 \pm 0.10$ & & $n / a$ & & 1.34 & \pm & 0.09 \\
\hline & 145632 & -10 & $8.1 \pm 0.4$ & 12 & 8 & $3.1 \pm 0.4$ & $121 \pm$ & \pm 13 & 109 & & $n / a$ & & & 3.4 & \pm 0.3 & & $36 \%$ & \pm 0.06 & 7 & $5.2 \pm 0.4$ & $2.0 \pm 0.2$ & & $n / a$ & & & \pm & 0.2 \\
\hline Adjacent mound & 145633 & $0.1^{\mathrm{a}}$ & $1.47 \pm 0.08$ & 3 & 61 & $0.74 \pm 0.11$ & $113 \pm$ & \pm 13 & 201 & -0.06 & \pm 0.0 & .05 & $30 \%$ & & $\mathrm{n} / \mathrm{a}$ & & & $n / a$ & 5 & $1.14 \pm 0.10$ & $0.58 \pm 0.09$ & -0.05 & \pm 0 & .04 & & $\mathrm{n} / \mathrm{a}$ & \\
\hline & 145634 & $0.3^{\mathrm{a}}$ & $2.71 \pm 0.06$ & 2 & 35 & $1.09 \pm 0.12$ & $98 \pm$ & \pm 7 & 200 & -0.10 & \pm 0.0 & .09 & $18 \%$ & & n/a & & & n/a & 8 & $1.56 \pm 0.10$ & $0.63 \pm 0.07$ & -0.06 & \pm 0. & 0.05 & & $\mathrm{n} / \mathrm{a}$ & \\
\hline & 145635 & $0.7^{\mathrm{a}}$ & $3.0 \pm 0.4$ & 3 & 20 & $2.3 \pm 0.3$ & $110 \pm$ & \pm 16 & 182 & -0.02 & \pm 0.0 & .09 & $19 \%$ & & $n / a$ & & & $n / a$ & 11 & $1.9 \pm 0.3$ & $1.4 \pm 0.2$ & -0.01 & \pm 0 & .06 & & $\mathrm{n} / \mathrm{a}$ & \\
\hline
\end{tabular}

Summary of equivalent doses and ages. $n$ is the number of accepted aliquots/grains, nneg is the number of negative dose estimates, $C A M_{U L}$ is the weighted average calculated using the CAM $U$, $O D_{U L}$ is the corresponding over-dispersion. IEU is the Internal/external consistency minimum age model and nw.b. is the fraction of grains identified by the IEU to be well bleached. FMM is the most prominent dose component identified by the finite mixture model and $P$ is the associated proportion of grains in this component. Note that individual non-positive dose estimates have arbitrarily been discarded prior to running the FMM. Sat. is the fraction of grains appearing to be in saturation. 


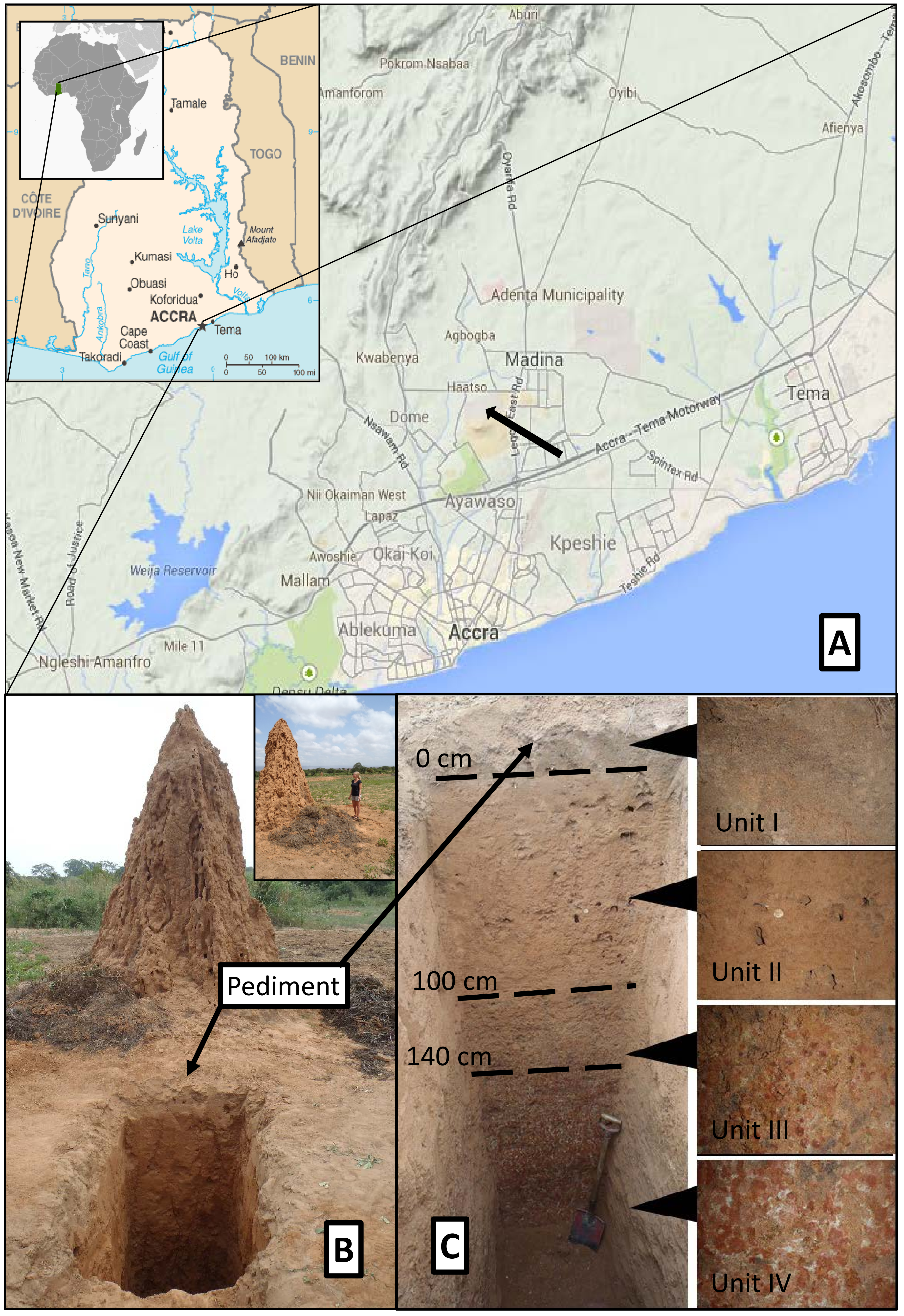




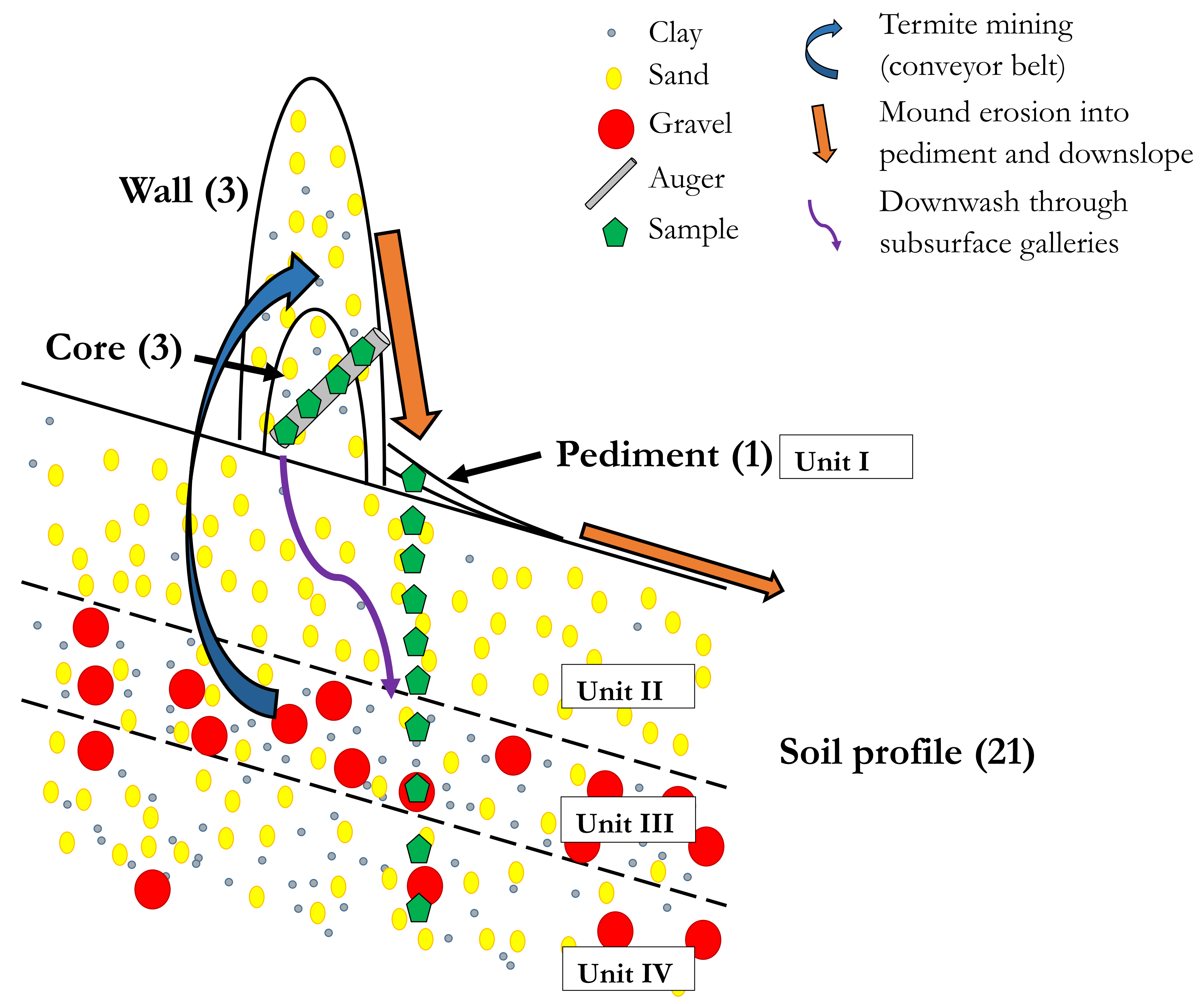




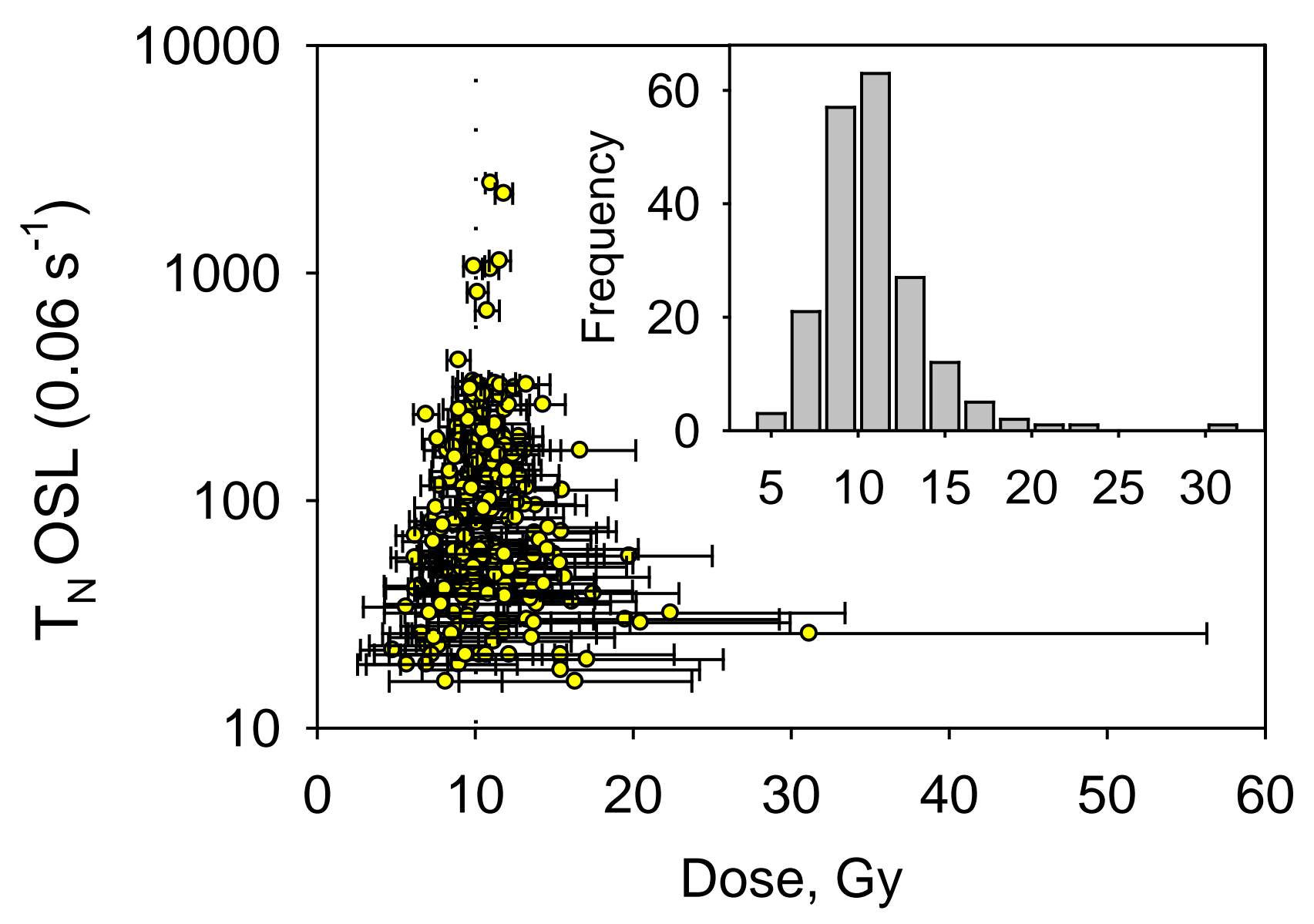



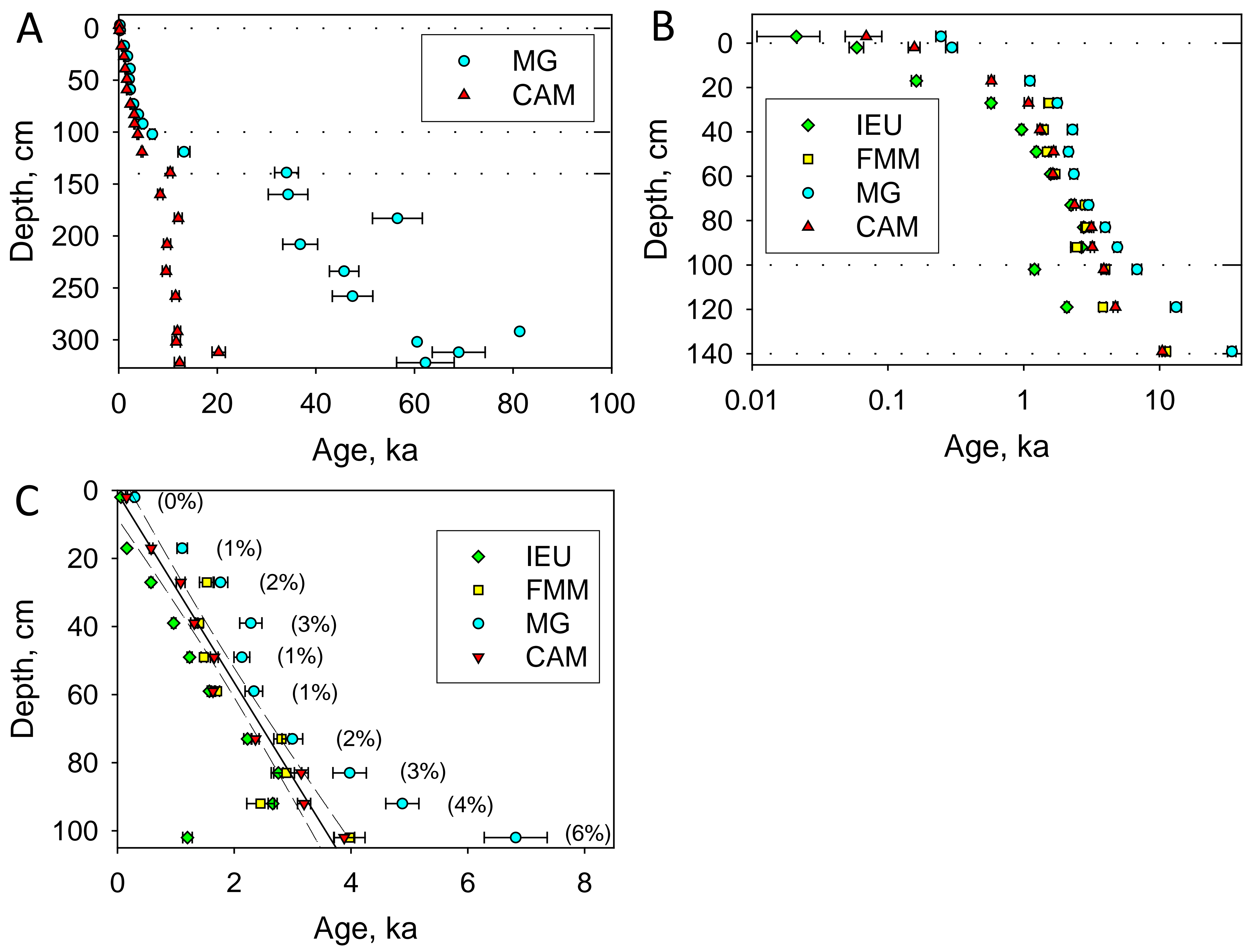

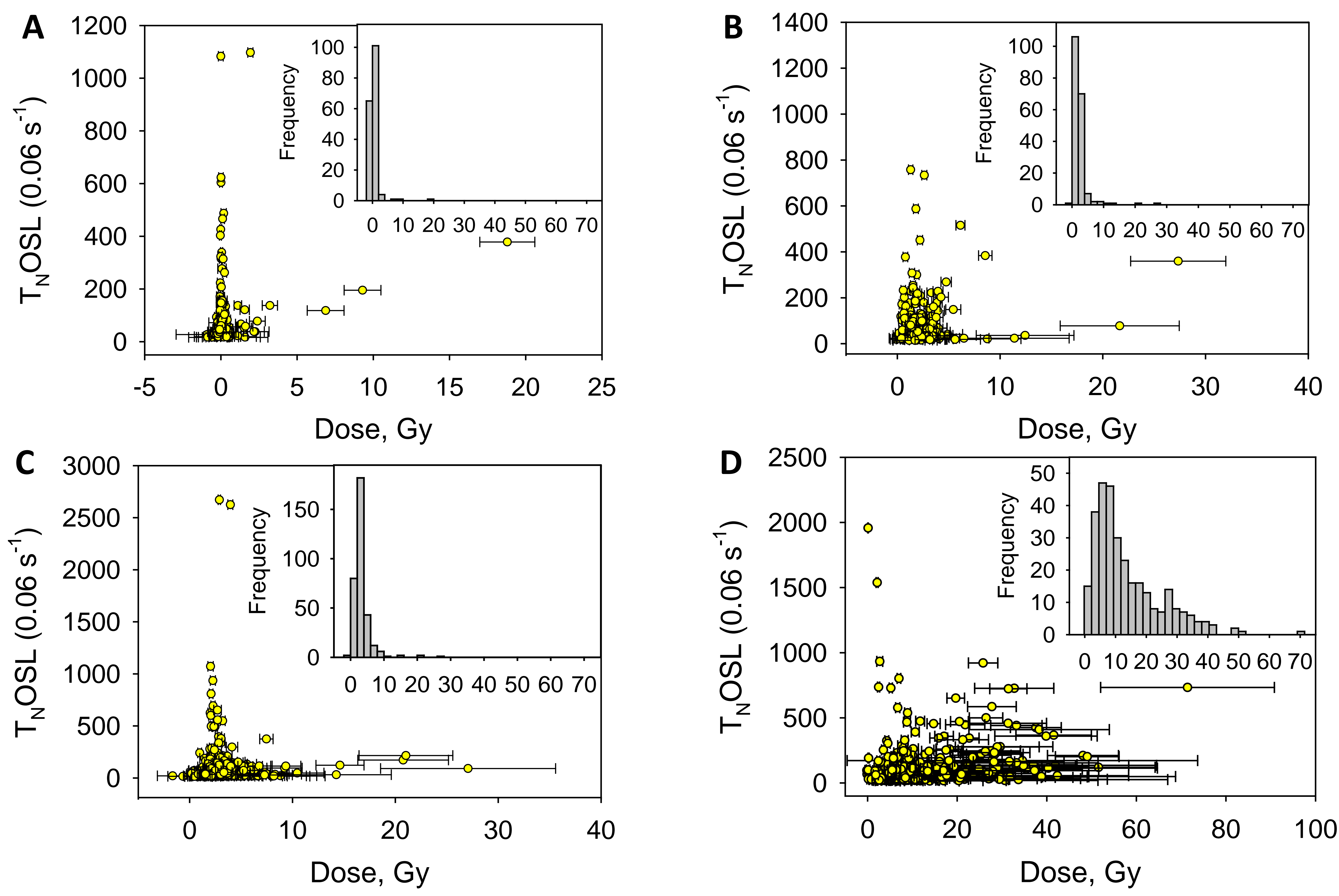


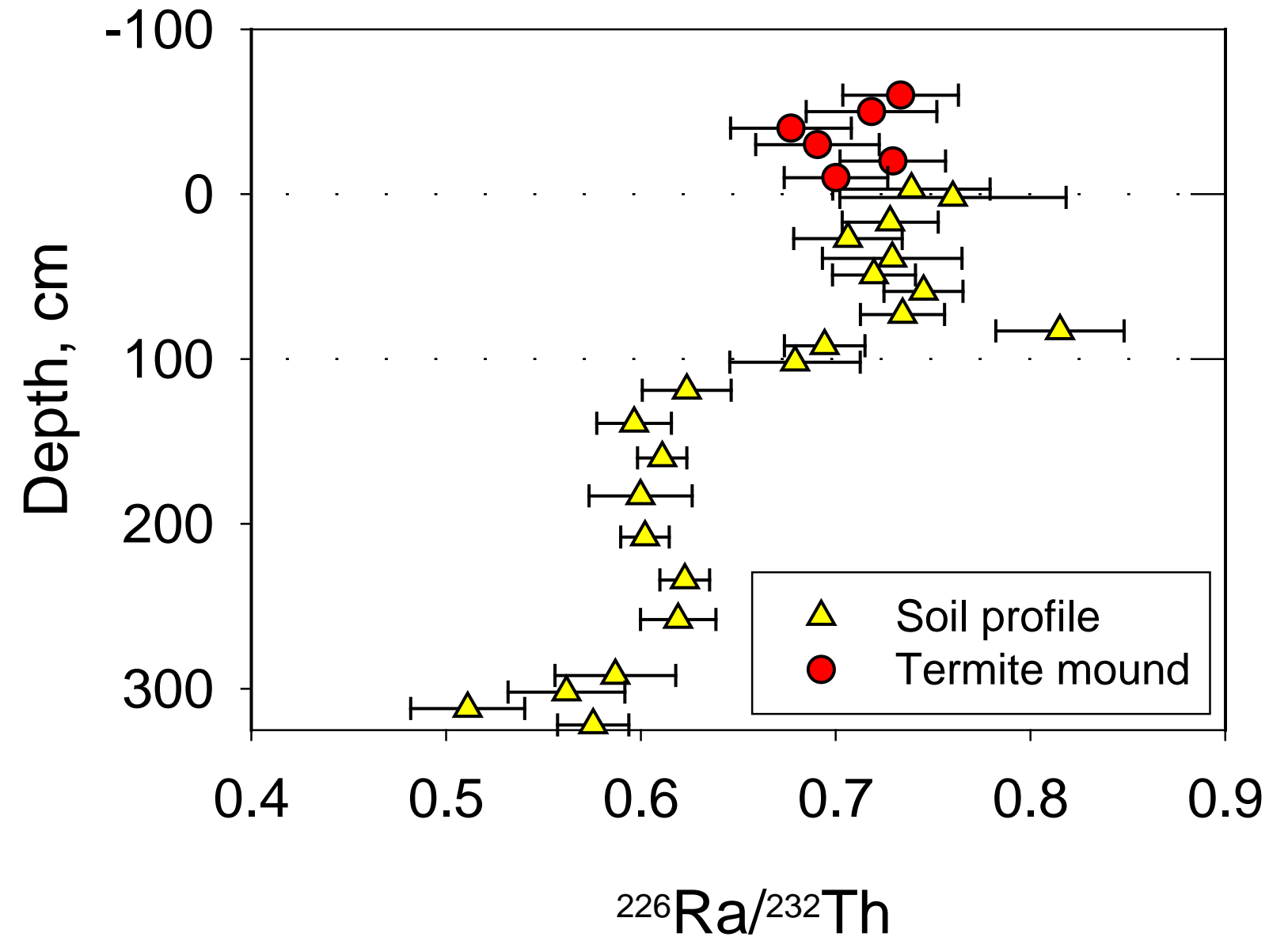




\section{Figure 1}

The study area. A) The location in Ghana. The black arrow points to the field site. B) The mound and the soil pit. Note the person in the inset $(\mathrm{c} .175 \mathrm{~cm}$ ) for scale. C) The soil profile with the four identified domains (unit I-IV, see Figure 2 for explanation): The mound pediment (unit I, above $0 \mathrm{~cm}$ ); the termite deposited layer (unit II, 0-100 cm); the (presumed) primary mining area (unit III, 100-140 cm) and; the plinthitic (lateritic) subsoil, which is believed to be untouched by the current termites (unit IV, below $140 \mathrm{~cm}$ ). Note the pale pediment on top of the old soil profile and the spade for scale (c. $120 \mathrm{~cm})$. Maps: Google Maps; University of Texas Library. Photo: Jeppe A. Kristensen

\section{Figure 2}

Conceptual model of the bioturbation system (not to scale). The green hexagons show approximate sample locations and density while the number in the brackets indicate the number of samples collected from unit I-IV. The density of clay, sand and gravel symbols indicate the relative particle size distribution in the individual units. Note the gravel free topsoil (unit I+II) presumed to consist of eroded mound material (buried pediments). The relative increase in gravel (iron nodules) in unit III is due to the upconcentration of gravel in the termite mining area due to their apparent inability to carry particles larger than roughly $1 \mathrm{~mm}$ in diameter (Awadzi et al., 2004). The units here correspond to the units in Figure 1C.

\section{Figure 3}

Multi-grain quartz luminescence characteristics. A) Typical dose response curve and decay curve (inset). Sample 145615 . The quartz is dominated by a fast component and the $\mathrm{D}_{0}$ is $36 \pm 2 \mathrm{~Gy}$. B) The recycling ratio for all samples, which is close to unity.

\section{Figure 4}

Single grain beta dose recovery for sample 145616, given dose = $10 \mathrm{~Gy}$ (dashed line). 193 grains out of 300 were accepted for further processing. The average dose recovery of the accepted grains is $1.03 \pm 0.02$ (CAM=0.99 \pm 0.01 ; over-dispersion of $10.51 \pm 0.15 \%)$.

\section{Figure 5}

The age distribution down the soil profile. A) multi-grain (MG) and single-grain (SG) CAM ages. Note the increase in age and scatter in the MG data below $140 \mathrm{~cm}$ (unit IV). B) The age distributions in the upper $140 \mathrm{~cm}$ for both MG (circles) and SG (diamonds, squares and triangles) data. IEU (diamonds) is the single-grain minimum ages calculated using the IEU model (Thomsen et al. 2003; 2007), FMM (squares) is the Finite Mixture Model (Galbraith and Green, 1990) single-grain ages calculated using and OD of 20\% (see text for details) and CAM (triangles) are the Central Age Model (Galbraith et al., 1999) single-grain ages. Note the relatively young IEU ages in the 100-140 cm interval (unit III) indicating downward mixing of young surface grains. Note the log scale on the $x-$ axis C) The same data as in B but only shown for the $0-100 \mathrm{~cm}$ interval (unit II). The numbers in brackets indicate the fraction of saturated grains in each sample attributed to upward mixing. The solid straight line is regressed linearly through the CAM data set $\left(R^{2}=0.97\right)$ and the dashed lines show $95 \%$ confidence intervals.

\section{Figure 6}

Single grain dose distributions. A) mound pediment, $-3 \mathrm{~cm}$ (unit I, \#145605); B) soil profile, $39 \mathrm{~cm}$ (unit II, \#145609); C) soil profile, $59 \mathrm{~cm}$ (unit II, \#145611); D) soil profile, $119 \mathrm{~cm}$ (unit III, \#145616). Note the different scales on the main $x$-axis and the same scale on the histogram $x$-axis in the inset.

\section{Figure 7}

${ }^{226} \mathrm{Ra} /{ }^{232} \mathrm{Th}$ in the termite mound and the soil profile. The ratio in the mound is indistinguishable from the top $100 \mathrm{~cm}$ (unit I+II) but different from the sediment below $100 \mathrm{~cm}$. Uncertainties represent one standard error.

\section{Table 1}

Summary of observed water content (w.c.), and radionuclide concentrations used to calculate the total quartz dose rates. Uncertainties represent one standard error.

\section{Table 2}

Summary of equivalent doses and ages. $\mathrm{n}$ is the number of accepted aliquots/grains, $\mathrm{n}_{\text {neg }}$ is the number of negative dose estimates, $C_{C A M}$ is the weighted average calculated using the CAM ${ }_{U L}, O D_{U L}$ is the corresponding over-dispersion. IEU is the Internal/external consistency minimum age model and $n_{w . b}$. is the fraction of grains identified by the IEU to be well bleached. FMM is the most 
prominent dose component identified by the finite mixture model and $\mathrm{P}$ is the associated proportion of grains in this component. Note that individual non-positive dose estimates have arbitrarily been discarded prior to running the FMM, and if they constituted more than $5 \%$ of $n$, the sample was omitted from the calculation. Sat. is the fraction of grains appearing to be in saturation. 